\title{
Spatio-temporal Changes of Land Use from 1989 to 2009 and Its Driving Forces in Jiangsu Coastal Areas, China
}

\author{
Bing LI, Haisuo WU, Shui WANG, Ying TIAN, Changsheng QU* \\ Jiangsu Provincial Academy of Environmental Science \\ Nanjing, China \\ quchsh@hotmail.com
}

\begin{abstract}
The spatial distribution and dynamic change of land use and land cover are analyzed over a 20 years span based on multi-temporal satellite data from 1989, 1995 and 2009. During the period from 1989 to 2009 , built-up area and water body increased, whereas agricultural land and mudflat decreased. Urban settlement area increased nearly 5 times, mainly due to the city expansion, and mainly transformed from agricultural land. Land use dynamic degree analysis shown that loss speed of mudflat and agricultural land accelerated over the last two decades. It is demonstrated that human activities and social influences are main driving forces contributing to dynamic changes in land use and land cover in the last two decades in Jiangsu coastal area.
\end{abstract}

Index Terms-LUCC, spatio-temporal change, driving forces, coastal area

\section{INTRODUCTION}

Land is the most fundamental concern for indigenous peoples around the world [1]. Among different land types, coastal area is quite special for its combining geomorphic, oceanographic, terrestrial and anthropogenic attributes [2,3]. In order to provide basis for the coastal land-use decisions, LUCC analysis has been used widely to determine the present condition, potential for use and interest for conversation in coastal areas [4,5].

Eastern coastal areas are China's most populated and developed parts, especially with the onset of the reform and opening up policy [6]. With vast shoals resources, abundant labor force and advantageous geographical position, less developed Jiangsu coastal area is chosen as new priority development region. And it has already been improved as a national strategy since 2009 to turn this area into a new economic growth pole in east China. There are already 31 built industrial parks in this area, mainly focused on chemical industry, iron and steel industry, shipbuilding industry, and grain and oil processing industry. Under this new situation of implementing coast development strategy in Jiangsu Province, conflicts between human and nature there may become sharper, and the unique land-sea ecosystem and biodiversity may be affected in the process of industrialization and urbanization. The general objectives of this study were: (1) to examine the dynamics of land-use change in the study area; (2) to explore the driving factors and mechanism of LUCC and (3) to provide useful information for decision makers to take appropriate land-use management measures in Jiangsu coastal area.

\section{MATERIALS AND METHODS}

\section{A. Study area}

Located in the eastern part of Jiangsu Province, the study area is on the shore of the Yellow Sea, with a coastline of 954 $\mathrm{km}$, and faces Japan and Korea opposite of Yellow Sea (Fig. 1). It covers an area of $28,400 \mathrm{~km}^{2}$, and includes 17 towns of three cities, Lianyungang, Yancheng and Nantong.

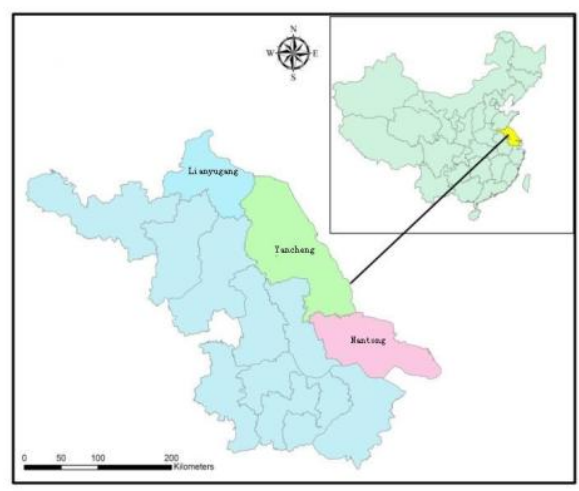

Fig.1. Location of study area.

\section{B. Data sources and processing}

Data used in this study can be classified into two groups. Group 1, for interpreting and acquiring LUCC information, were extracted from Landsat Thematic Mapper (TM) images (with a resolution of $28.5 \mathrm{~m} \times 28.5 \mathrm{~m}$, Fig. 2) and topographic map over a twenty-year time span, including three dates, 1989 , 1995 and 2009. Group 2, for analyzing driving factors of LUCC, economic and social data were mainly collected from city-level statistical yearbooks, and geographic data were extracted from traffic map, drainage map and elevation map of Jiangsu Province.

All the TM data used in the study were interpreted by the same remote sensing analyst, who applied a standard classification methodology to ensure repeatability and consistency. Erdas-AOI-seeds tool was applied for the 
geometry rectification of remote sensing imagery. In view of the rugged and fragmental topography in the study area, field investigations were performed and GPS points were acquired in the study area to guarantee the accuracy of interpretation. GIS software (ArcGIS 9.2) was used to conduct spatial analysis, including digitization, rasterization, interpretation, overlaying and map calculations of various map features. Nine land-use types, namely agricultural land, woodland, water body, river, urban settlement, rural settlement, construction land mainly for transportation, mudflat and unused land were identified and delineated in each map.

\section{Land use changes detection methods}

In order to explore the temporal and spatial patterns of land use, 4 metrics were chosen for study on the basis of literature reviews and relevance to this research [4,7-9].

- Transfer out ratio of single land use

This index reflects the transformation extent of a specific land use type changed to others over the study period. It is calculated as follows:

$$
T_{i}=\frac{\sum_{j=1}^{n-1} T_{i j}}{L_{t o}} \times 100 \%
$$

where $T_{i}$ stands for change ratio of land type $i$ to other land use types from period $t_{0}$ to $t_{k} ; T_{i j}$ is regional area changed from land use $i$ to $j$ over the study period; $L_{t 0}$ is area of land use $i$ at the given monitoring time $t_{0} ; n$ is the sum of all the land use types in this region.

- Transfer in ratio of single land use

This index characterizes the transformation extent of a specific land use type transformed from others over the study period. It can be expressed as:

$$
M_{i}=\frac{\sum_{j=1}^{n-1} M_{i j}}{L_{t k}} \times 100 \%
$$

where $M_{i}$ stands for change ratio of land type $i$ from other land use types from period $t_{0}$ to $t_{k} ; M_{i j}$ is the regional area changed from land use $j$ to $i$ over the study period; $L_{t k}$ is area of land use $i$ at the given monitoring time $t_{k}$.

- $\quad$ Single land use dynamic degree

This index measures the area change rate of a specific land use type over the study span. It is calculated as follows:

$$
K=\frac{U_{b}-U_{a}}{U_{a}} \times \frac{1}{T} \times 100 \%
$$

where $K$ is the single land use dynamic degree; $U_{a}$ and $U_{b}$ are areas of a specific land use type at the beginning and end of the study period respectively; $T$ is the study time span.

- Integrated land use dynamic degree

This index characterizes the overall situation of various changes in the study area. It shows that the larger the value, the stronger the change. It can be expressed as:

$$
L I=\left[\frac{\sum_{i=1}^{n} \Delta L U_{i j}}{\sum_{i=1}^{n} L U_{i}}\right] \times \frac{1}{T} \times 100 \%
$$

where $L I$ stands for the integrated land use dynamic degree; $L U_{i}$ is the area of land type $i$ at the beginning of the monitoring period; $\Delta L U_{i j}$ is the changed area of land type $i$ to others in the study period.

\section{Driving forces analysis}

There are a variety of driving forces that impact land use and land cover, and these interact dynamically to give rise to different sequences and trajectories of change, depending upon the specific environmental and social context [10]. On the basis of literature reviews [11-12], local conditions and data availability in study area, 10 variables were selected as economic driving factors, including population density (PD)、 working population density (WPD)、 fiscal revenue per unit area (FR)、 grain output per unit area (GO)、 distance to port (DTP) 、 distance to main road (DTMR) 、 distance to secondary road (DTSR) 、 distance to urban settlement (DTUS)、 distance to county settlement (DTCS) and distance to rural settlement (DTRS), and 4 variables were selected as economic driving factors, including elevation (EL)、 slope (SL) 、 distance to water (DTW) and distance to sea wall (DTSW). To improve the pertinency and accuracy of driving forces analysis, land use types were simplified to 4 kinds, including build-up land, wood land, agricultural land and wetland according to the national land use classification system. As an important statistical tool of analyzing continuous data, discrete data and contingency table data, Logistic regression equation was applied in this study to reveal the driving forces of land use changes. And then ROC (relative operating characteristics) was used to verify regression equation's explanation ability.

\section{RESULTS AND DISCUSSION}

\section{A. Spatio-temporal differentiation of land use}

The land-use maps for 1989, 1995 and 2009 are presented in Fig. 2. shows land use structure in Jiangsu coastal area. The present study area spreads to an aerial extent of $31,424 \mathrm{~km}^{2}$. Because the near-shore area is siltation-rise pattern, the total area is not changeless, which increased $7.92 \%$ from 1989 to 2009, due to the mudflat siltation eastward.

Agricultural land was the main land use type, accounting for more than $80 \%$, while the proportion was decreased from $84.61 \%$ in $1989,84.20 \%$ in 1995 to $80.55 \%$ in 2009 continuously. On the contrary, build-up area increased sharply. During 1989-2009, urban settlement area increased nearly 5 times, as much as $1099 \mathrm{~km}^{2}$, mainly due to the expansion of the city of Nantong, Yancheng and Lianyungang. Among these three cities, Nantong and Yancheng expanded faster than Lianyungang. Rural settlement also had a stable and fast increase in twenty years from $701 \mathrm{~km}^{2}$ to $1027 \mathrm{~km}^{2}$. The towns in Lianyungang were the densest in the study area. For mudflat, the tendency was in the opposite direction. Between 1989 and 2009 , mudflat was with the largest rate of decrease among all the land use types. In 2009, it only accounted for $0.60 \%$ of the total land area, and was the smallest land use type. Water bodies, rivers and woodland decreased during 1989-1995 but increased for 1995-2009. Water bodies and woodland were mainly located in the northern part of Jiangsu coastal area. 


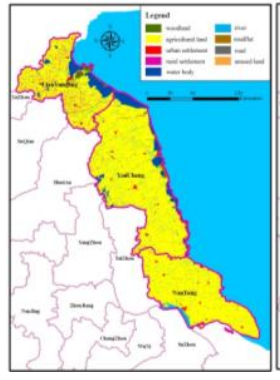

1989

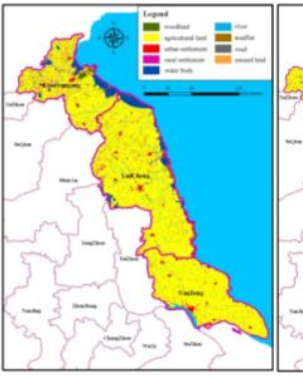

1995

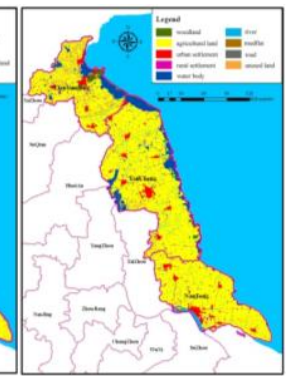

2009
Fig.2. Land use of Jiangsu coastal areas in 1989, 1995 and 2009.

Agricultural land was the main land use type, accounting for more than $80 \%$, while the proportion was decreased from $84.61 \%$ in $1989,84.20 \%$ in 1995 to $80.55 \%$ in 2009 continuously. On the contrary, build-up area increased sharply. During 1989-2009, urban settlement area increased nearly 5 times, as much as $1099 \mathrm{~km}^{2}$, mainly due to the expansion of the city of Nantong, Yancheng and Lianyungang. Among these three cities, Nantong and Yancheng expanded faster than Lianyungang. Rural settlement also had a stable and fast increase in twenty years from $701 \mathrm{~km}^{2}$ to $1027 \mathrm{~km}^{2}$. The towns in Lianyungang were the densest in the study area. For mudflat, the tendency was in the opposite direction. Between 1989 and 2009 , mudflat was with the largest rate of decrease among all the land use types. In 2009, it only accounted for $0.60 \%$ of the total land area, and was the smallest land use type. Water bodies, rivers and woodland decreased during 1989-1995 but increased for 1995-2009. Water bodies and woodland were mainly located in the northern part of Jiangsu coastal area.

\section{B. Land use transformation}

The land use and land cover change areas between 1989 and 1995 were shown in Fig. 3. During the first 6 years of the study period, build-up land increased quickly, especially the fast expanding of rural and urban settlement. Settlement refers to the occupation of land for human living space. As land cover, settlement represents the most profound human alteration of the natural environment through the imposition of structures, buildings, paved surfaces and compacted bare soils on the ground surface [13]. Its increase was at the cost of the decrease of agricultural land, water body and river. Among all the land use types, water body shrank most during this period, mainly due to the transformation to agricultural land through lake and sea reclamation in this area.

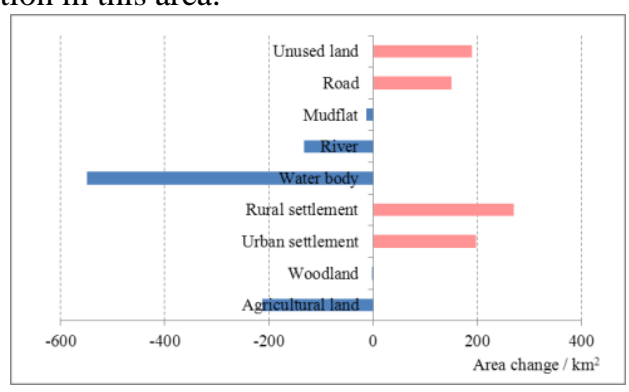

Fig. 3. LUCC between 1989 and 1995.

The land use and land cover change areas between 1995 and 2009 were presented in Fig. 4. Urban land expansion and structure change are important characters in the process of urbanization during this period. In these 14 years, because of the urban planning strategy, industrial and public construction land occupied the main sector of the total land expansion, whereas rural area expanded much less. During 1995-2009, there was an obviously increase of water bodies at the northern coastal area and the west of Yancheng city. They transformed from agricultural land and mudflat there correspondingly, and this may be attributed to the fast aquaculture development. Moreover, during this period, agricultural land decreased persistently, which mainly transformed to build-up land and construction area. Mudflat along the coastal line shanked $57.8 \%$, from $448.31 \mathrm{~km}^{2}$ in 1995 to $188.96 \mathrm{~km}^{2}$ in 2009 . It dominantly transformed to water body for enclosure culture and agricultural production.

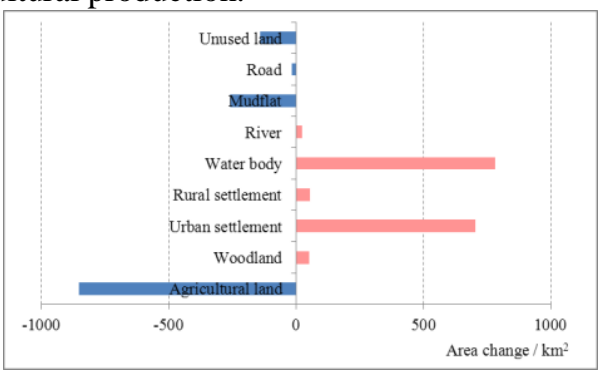

Fig. 4. LUCC between 1995 and 2009

Single land use dynamic degree characterized the land use transformation speed. The value of mudflat increased from 0.48 in the first period to -4.13 in the second period, and that of agricultural land increased from -0.13 to -0.23 , indicating an accelerated loss speed for mudflat and agricultural land in Jiangsu coastal area. Although total loss amount was huge, the transformation speed of agricultural land was relatively steady compared to others. Urban settlement was the fastest transformed land use type, for its dynamic degree was as high as 16.60 and 12.70 in two study period respectively. Compared to urban settlement, rural settlement's changed not that sharply. As for annual transfer out ratio, all land use types transferred to others slower in the second period than the first period. Transfer in ratio had a similar trend except for water body. Among different land use types, road, urban and rural settlement transferred from others much faster. The transfer in ratios of them was about $10 \%$ annually between 1989 and 1995 , and about 5\% annually between 1995 and 2009. However, transfer in ratios of agricultural land and mudflat was much less than others, which only reached $0.37 \%$ and $1.39 \%$ respectively during 1995-2009. These results demonstrated that rapid increases in built-up land were associated with largescale agricultural land and mudflat degradation, have been prominent in the second study period when the eastern coastal development policy was implemented.

\section{Driving factors}

Regression analysis between area changes of each land use type and the potential driving factors were processed. Logistic regression analysis results were presented in Table 1. Each ROC value was larger than 0.75 , indicating driving forces model's well explanation ability. 
TABLE I. REGRESSION ANALYSES RESULTS (EXPB)

\begin{tabular}{|c|c|c|c|c|c|}
\hline \multicolumn{2}{|c|}{ Factors } & $\begin{array}{c}\text { Build- } \\
\text { up } \\
\text { land }\end{array}$ & Wetland & $\begin{array}{c}\text { Agricultural } \\
\text { land }\end{array}$ & Woodland \\
\hline \multirow{3}{*}{$\begin{array}{c}\text { Geogra- } \\
\text { phical } \\
\text { factors }\end{array}$} & EL & - & - & - & $1.307^{* *}$ \\
\cline { 2 - 6 } & SL & - & - & $0.779^{*}$ & 1.298 \\
\cline { 2 - 6 } & DTW & $0.987^{*}$ & 0.761 & 1.122 & - \\
\cline { 2 - 6 } & DTSW & 1.162 & 0.794 & 1.115 & $0.535^{*}$ \\
\hline \multirow{4}{*}{$\begin{array}{c}\text { Social- } \\
\text { factors }\end{array}$} & DTP & 1.125 & - & - & $0.682^{*}$ \\
\cline { 2 - 6 } & DTMR & 0.635 & $0.779^{*}$ & 0.596 & - \\
\cline { 2 - 6 } & DTSR & $0.407^{* *}$ & $1.182^{*}$ & $1.478^{*}$ & - \\
\cline { 2 - 6 } & DTUS & 0.932 & - & - & 0.335 \\
\cline { 2 - 6 } & DTCS & 1.398 & 0.768 & 0.611 & $1.820^{*}$ \\
\cline { 2 - 6 } & DTRS & $0.466^{* *}$ & -1.898 & 0.550 & - \\
\cline { 2 - 6 } & FR & $1.241^{*}$ & $0.949^{*}$ & 0.913 & - \\
\cline { 2 - 6 } & GO & 1.304 & -1.775 & 0.678 & - \\
\cline { 2 - 6 } & WPD & 1.264 & 0.861 & 1.088 & - \\
\cline { 2 - 6 } & PD & 1.672 & $1.803^{*}$ & $0.422^{*}$ & - \\
\cline { 2 - 6 } & ROC & 0.787 & 0.771 & 0.758 & 0.996 \\
\hline \multirow{2}{*}{$*: P<0.05 ; * *: P<0.01$} & & & \\
\cline { 2 - 6 } & & & & & \\
\hline
\end{tabular}

The results showed: build-up land area was highly relative with DTW $(\mathrm{P}<0.05)$, which indicated that the spatio-temporal distribution of surface water is one of the key factors influencing changes in build-up land use [14], and the dense river network in Jiangsu coastal area facilitate the settlement construction. Distance to secondary road (DTSR, $\mathrm{P}<0.01$ ), distance to rural settlement (DTRS, $\mathrm{P}<0.01$ ) and fiscal revenue FR (FR, $\mathrm{P}<0.05)$ also significantly drove the build-up land use change, reflecting that the effect of factitious factors, such as economy, population and transport policy. As to wetland, it was relative with population density $(\mathrm{PD}, \mathrm{P}<0.05)$, fiscal revenue $(\mathrm{FR}, \mathrm{P}<0.05)$, distance to main road $(\mathrm{DTMR}, \mathrm{P}<0.05)$ and distance to secondary road (DTSR, $\mathrm{P}<0.05$ ), indicating that population, economic development and traffic construction reduced the wetland area evidently. As an import land attribute, slope $(\mathrm{SL}, \mathrm{P}<0.05)$ influenced the agricultural land change. Distance to secondary road (DTSR, $\mathrm{P}<0.05)$ and population density ( $\mathrm{PD}, \mathrm{P}<0.05)$, as the characterization of rural traffic construction and population increase, drove the reduction of agricultural land area. For woodland, it was easy to understand that elevation $(\mathrm{EL}, \mathrm{P}<0.01)$ was an important driving factor. Besides that, distance to county settlement (DTCS, P<0.05), distance to port (DTP, $\mathrm{P}<0.05)$ and distance to sea wall (DTSW, $\mathrm{P}<0.05$ ) were also significant driving factors for woodland change, which proved the fact that woodland was mainly located in counties in the northern coastal area. After all, regression analysis demonstrated that human activities and social influences are main driving forces contributing to dynamic changes in land use and lands cover in the last two decades in Jiangsu coastal area.

\section{CONCLUSIONS}

This study quantitatively analyzed spatio-temporal changes in land use and land cover in Jiangsu coastal area of east China by comparing classified satellite images over a 20 years span from 1989, 1995 and 2009. The results show an increase in built-up area and water body and a decrease in agricultural land and mudflat during 1989-2009. Over the study period, urban settlement area increased nearly 5 times, mainly due to the expansion of the city of Nantong, Yancheng and Lianyungang. During 1995-2009, water bodies increase sharply at the northern coastal area and the west of Yancheng city owing to the fast aquaculture development. Land use dynamic degree analysis shown that loss speed of mudflat and agricultural land accelerated over the last two decades, which were transformed to built-up land and water body mainly.

Driving forces analysis reveals that human activities influence the land use and land cover change dominantly, indicating urbanization, population increase and eastern coastal development policy are main driving forces contributing to dynamic changes in land use and lands cover pattern in the last two decades in Jiangsu coastal area. In order to reduce the gap between the present state and desired state of land use in the coastal areas during the great development process, it is suggested that the expansion of build-up land and water body development for enclosure culture over agricultural land and mudflat should be better managed. Furthermore, as an important wintering ground for migrant birds and habitat region of wild life, more attentions should be paid on local unique land-sea ecosystem. The eco-environmental impacts posed by the land use change worth indepth study in the future.

\section{ACKNOWLEDGMENT}

This study is supported by National Meta-Program for Science \& Technology of Water Pollution Control (No. 2012ZX07506-001), National Natural Science Foundation (No. 41201545) and Jiangsu Science Foundation (No. BM2010599 \& BK2009454).

\section{REFERENCES}

[1] R. DeFries, G.P. Asner, and J. Foley, "A glimpse out the window: Landscapes, livelihoods and the environment," Environment: Science and Policy for Sustainable Development, 2006, 48(8): 22-36.

[2] H. Eggert, and B. Olsson, "Valuing multi-attribute marine water quality," Marine Policy, 2009, 33(2): 201-206.

[3] F. Gazeau, S.V. Smith, B. Gentili, M. Frankignoulle, and J.P. Gattuso, "The European coastal zone: characterization and first assessment of ecosystem metabolism," Estuarine, Coastal and Shelf Science, 2004, 60(4): 673-694.

[4] J. Huang, Z. Tu, and J. Lin, "Land-use dynamics and landscape pattern change in a coastal gulf region, southeast China," International Journal of Sustainable Development \& World Ecology, 2009, 16(1): 61-66.

[5] A. Vallega, "From Rio to Johannesburg: The role of coastal GIS," Ocean \& Coastal Management, 2005, 48(7-8): 588-618.

[6] J. Liu, J. Zhan, and X. Deng, "Spatio-temporal patterns and driving forces of urban land expansion in China during the economic reform era," AMBIO: Journal of the Human Environment, 2005, 34(6): 450-455.

[7] X. Wang, and Y. Bao, "Study on the methods of land use dynamic change research," Progress in Geogrophy, 1999,18(1): 81-87. 
[8] X. Yu, and G. Yang, "The advances and problems of land use and land cover change research in China," Progress in Geogrophy, 2002, 21(1): 51-57.

[9] H. Zhu, and X. Li, "Discussion on the index method of regional land use change," Acta Geographica Sinica, 2003, 58(5): 643650.

[10] H. Nagendra, D.K. Munroe, and J. Southworth, "From pattern to process: landscape fragmentation and the analysis of land use/land cover change," Agriculture, Ecosystems \& Environment, 2004, 101(2-3): 111-115.

[11] A. Kelarestaghi, and Z. Jafarian Jeloudar, "Land use/cover change and driving force analyses in parts of northern Iran using
RS and GIS techniques," Arabian Journal of Geosciences, 2011, 4(3): 401-411.

[12] E.F. Lambin, B.L. Turner, H.J. Geist, S.B. Agbola, A. Angelsen, J.W. Bruce, O.T. Coomes, et al., "The causes of land-use and land-cover change: moving beyond the myths," Global Environmental Change, 2001, 11(4): 261-269.

[13] S. Fazal, "Urban expansion and loss of agricultural land-a GIS based study of Saharanpur City, India," Environment and Urbanization, 2000, 12(2): 133-149.

[14] J.L. Kok, G. Engelen, R. White, and H.G. Wind, "Modeling land-use change in a decision-support system for coastal-zone management," Environmental Modeling and Assessment, 2001, 6(2):123-132. 